\title{
Penyuluhan Mengenai Ketahanan Pangan Rumah Tangga Sebagai Upaya Pencegahan Masalah Gizi Kronis (Stunting) di Wanita Kaum Ibu (WKI) Jemaat GMIST Immanuel Dame Kabupaten Sitaro
}

\author{
Yulianty Sanggelorang ${ }^{1}$, Asep Rahman ${ }^{2}$ \\ 1,2Program Studi Ilmu Kesehatan Masyarakat, Fakultas Kesehatan Masyarakat, \\ Universitas Sam Ratulangi Manado, 95115, Sulawesi Utara, Indonesia \\ Penulis korespondensi: Yulianty Sanggelorang, Program Studi IKM, FKM Unsrat \\ Email: y.sanggelorang@unsrat.ac.id
}

\begin{abstract}
ABSTRAK
Ketahanan pangan rumah tangga merupakan salah satu faktor yang mempengaruhi status kesehatan, secara khusus status gizi anggota rumah tangga. Masalah gizi kronis (stunting) lebih banyak ditemukan pada anak yang dari kelompok rumah tangga rawan pangan dibandingkan tahan pangan. Masalah ini muncul salah satunya karena kurangnya pengetahuan mengenai ketahanan pangan rumah tangga. Tujuan dari kegiatan ini yaitu untuk meningkatkan pengetahuan masyarakat khususnya ibu-ibu tentang ketahanan pangan. Metode pelaksanaannya yaitu penyuluhan dan pembagian brosur. Luaran kegiatan ini yaitu peningkatan pengetahuan yang diukur dengan instrumen kuesioner (pretest dan posttest). Deskripsi data menunjukan bahwa sebanyak 72,7\% peserta kegiatan yang pada pretest tingkat pengetahuannya kurang baik menjadi baik pada hasil post test, analisis lanjut dengan menggunakan Wilcoxon Signed Rank Test menunjukan bahwa terdapat perbedaan bermakna antara kelompok pretest dan posttest. Sehingga dapat disumpulkan bahwa kegiatan penyuluhan berhasil dengan baik dan lewat peningkatan pengetahuan ini peserta diharapkan dapat mengaplikasikan teori.
\end{abstract}

\section{Kata Kunci: ketahanan pangan rumah tangga, gizi kurang}

\section{PENDAHULUAN}

\section{Analisis Situasi}

Ketahanan pangan menentukan akses individu terhadap makanan yang diperlukan untuk memenuhi kebutuhan gizinya, sehingga hal ini menjadi penting untuk menentukan individu tersebut dapat hidup aktif dan sehat. Sehingga akhirnya, ketahanan pangan akan menjamin ketahanan gizi (Adriani and Wirjatmadi, 2012; Pee, 2013). Menurut UU No. 18 tahun 2012, Ketahanan Pangan adalah

"Kondisi terpenuhinya pangan bagi negara sampai dengan perseorangan, yang tercermin dari tersedianya pangan yang cukup, baik jumlah maupun mutunya, aman, beragam, bergizi, merata, dan terjangkau serta tidak bertentangan dengan agama, keyakinan, dan budaya masyarakat, untuk dapat hidup sehat, aktif, dan produktif secara berkelanjutan".

Wilayah Kabupaten Sitaro sebagian besar merupakan wilayah kepulauan, sehingga akses ke setiap daerah membutuhkan alat transportasi berupa kapal laut yang sangat bergantung pada kondisi cuaca. Kondisi ini menyebabkan Kabupaten Sitaro menjadi daerah yang rawan pangan secara ekologi (Hapsari dan Rudiarto, 2017). 


\section{VIV ABIO}

Jurnal Pengabdian Multidisiplin

Jemaat GMIST Immanuel Dame yang berlokasi di Kabupaten Sitaro sudah pasti akan mengalami kondisi yang sama. Hasil penelitian tahun 2016 menunjukan bahwa terdapat 21,2\% rumah tangga di Kecamatan Siau Timur Kabupaten Sitaro (Desa Dame termasuk salah satu desa di kecamatan ini) yang termasuk dalam kategori rawan pangan.

Rawan pangan berarti tidak terpenuhinya ketahanan pangan dari wilayah, rumah tangga terlebih tingkat individu. Ketahanan pangan tingkat rumah tangga (ketersediaan, akses dan pemanfaatan) yang tidak terjamin juga menjadi salah satu faktor yang mempengaruhi kejadian stunting (Masrin dkk., 2014). Hasil Riskesdas tahun 2013 menunjukan bahwa prevalensi stunting di Kabupaten Sitaro sebesar 38,45\% atau lebih tinggi dari rata-rata nasional sebesar 37,3\%. Penelitian tahun 2016 yang dilakukan pada balita yang ada di Kecamatan Siau Timur menunjukan bahwa risiko kejadian stunting pada anak dari kelompok rumah tangga rawan pangan 5 kali lebih besar dibandingkan dengan anak dari kelompok tahan pangan.

Kekurangan gizi kronis pada anak dalam masa pertumbuhan dapat menyebabkan berbagai gangguan di masa yang akan datang, seperti rendahnya kemampuan kognitif yang akan menyebabkan rendahnya prestasi belajar, mempengaruhi di bidang ekonomi, seperti rendahnya kemampuan mencari nafkah, sehingga sulit keluar dari lingkaran kemiskinan dan dampak di bidang kesehatan adalah rendahnya tinggi badan, kemudian pada ibu-ibu dengan tinggi badan yang rendah berisiko melahirkan bayi dengan berat badan lahir rendah (BBLR), yang akhirnya lingkaran masalah ini akan terulang pada generasi selanjutnya (WFP, 2009).
Wanita Kaum Ibu (WKI) Jemaat GMIST Immanuel Dame juga dalam keluarga bertindak sebagai Ibu Rumah Tangga yang bertanggungjawab terhadap penyelenggaraan makan rumah tangga. Sehingga kelompok ini menjadi kelompok kunci dalam menjamin ketahanan pangan tingkat rumah tangga.

Berdasarkan fakta di atas, maka perlu untuk dilakukan upaya peningkatan pengetahuan Wanita Kaum Ibu terkait ketahanan pangan rumah tangga demi menjamin kualitas kesehatan anggota rumah tangga.

\section{Tujuan dan Manfaat Kegiatan}

Kegiatan pengabdian lewat penyuluhan ini bertujuan untuk meningkatkan pengetahuan Wanita Kaum Ibu mengenai ketahanan pangan rumah tangga, nantinya diharapkan melalui ibu-ibu ini status kesehatan anggota keluarga dapat ditingkatkan khususnya dapat mencegah masalah gizi kronis (stunting) pada anak.

\section{METODE PELAKSANAAN Sasaran Kegiatan Pengabdian}

Mitra pada kegiatan ini adalah Ibu Rumah Tangga yang tergabung dalam Wanita Kaum Ibu Jemaat GMIST Immanuel Dame. Status sebagai ibu rumah tangga yang pada umumnya bertanggungjawab sebagai penyelenggara makan keluarga memungkinkan dilakukan kegiatan penyuluhan terkait ketahanan pangan keluarga agar kelompok kunci ini dapat menerapkan kiat dan solusi yang ditawarkan guna menjamin ketahanan pangan keluarga masing-masing. 
VIVABIO

Jurnal Pengabdian Multidisiplin

\section{Lokasi Kegiatan Pengabdian}

Kegiatan dilakukan di Wanita Kaum Ibu (WKI) Jemaat GMIST Immanuel Dame, Desa Dame I, Kecamatan Siau Timur, Kabupaten Kepulauan Siau Tagulandang Biaro.

\section{Metode yang Digunakan}

Metode yang digunakan dalam kegiatan ini yaitu penyuluhan, juga ada pembagian brosur (lihat gambar 1) yang kontennya sama dengan konten materi penyuluhan. Materi mengenai ketahanan pangan rumah tangga dibahas dengan topik-topik sebagai berikut:

a. Pengertian ketahanan pangan rumah tangga

b. Pemetaan kerawanan pangan

c. Hubungan ketahanan pangan rumah tangga dengan kejadian stunting

d. Solusi masalah kerawanan pangan tingkat keluarga.

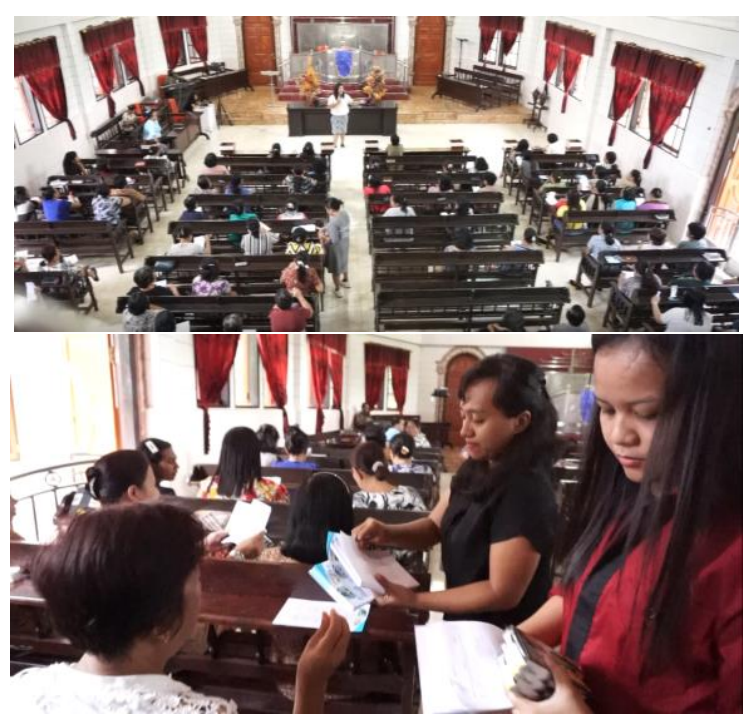

Gambar 1. Kegiatan Penyuluhan (atas)

Pembagian Brosur Berisi Materi

Mengenai Ketahanan Pangan

Rumah Tangga (bawah)

Penyuluhan diakhir dengan sesi tanya jawab. Guna menilai tingkat pengetahuan, peserta kegiatan mengisi kuesioner di awal (pretest) kegiatan penyuluhan (lihat gambar 2) dan kurang lebih 2 minggu (4 Agustus 2019) kuesioner yang sama dibagikan kepada ibu yang sama untuk kemudian dijawab kembali (posttest).

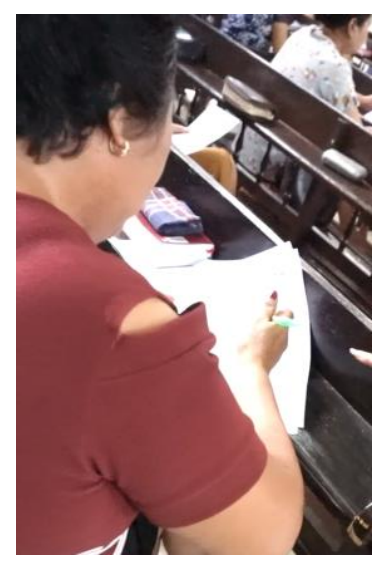

\section{Gambar 2. Peserta Kegiatan Sedang Mengisi Kuesioner}

\section{HASIL DAN PEMBAHASAN}

Peningkatan pengetahuan mengenai ketahanan pangan rumah tangga pada Wanita Kaum Ibu Jemaat GMIST Immanuel Dame melalui kegiatan penyuluhan telah terlaksana pada tanggal 21 Juli 2019 Pukul 14.00 - 17.00 WITA bertempat di Gedung Gereja Jemaat GMIST Immanuel Dame. Penyuluhan ini diikuti oleh 78 orang.

Kegiatan penyuluhan diharapkan dapat meningkatkan tingkat pengetahuan peserta kegiatan mengenai ketahanan pangan. Guna menilai tingkat pengetahuan ini, dilakukan pre dan posttest mengenai bahasan dalam penyuluhan yang dilakukan. Tabel berikut menunjukan tingkat pengetahuan peserta kegiatan pengabdian mengenai ketahanan pangan. 
VIVABIO

Jurnal Pengabdian Multidisiplin

Tabel 1. Gambaran Tingkat Pengetahuan Peserta Kegiatan Pengabdian

\begin{tabular}{llcc}
\hline & Kategori & n & \% \\
\hline Pre Test & Kurang Baik & 22 & 28,2 \\
& Baik & 56 & 71,8 \\
\hline Post & Kurang Baik & 6 & 7,7 \\
Test & Baik & 72 & 92,3 \\
\hline
\end{tabular}

Tabel 1 menunjukan bahwa terjadi peningkatan pengetahuan, terlihat dengan penurunan persentase peserta kegiatan PKM yang dalam kategori pengetahuan kurang baik (28,2\% menjadi 7,7\%). Lebih jelasnya mengenai distribusi perubahan tingkat pengetahuan peserta PKM dapat dilihat pada tabel berikut

Tabel 2. Perubahan Tingkat Pengetahuan Peserta Kegiatan PKM

\begin{tabular}{ccccc} 
& \multicolumn{2}{c}{ Post Test } & & pre Test \\
\cline { 2 - 3 } & $\begin{array}{c}\text { Kurang } \\
\text { Baik }\end{array}$ & Baik & Total & $\begin{array}{c}\text { praue } \\
*\end{array}$ \\
\hline Kurang & 6 & 16 & 22 & \\
Baik & $(27,3 \%)$ & $(72,7 \%)$ & $(100 \%)$ & \\
Baik & $0(0 \%)$ & $\begin{array}{c}56 \\
(100 \%)\end{array}$ & $\begin{array}{c}56 \\
(100 \%)\end{array}$ & 0,000 \\
\cline { 1 - 3 } Total & $6(7,7 \%)$ & $\begin{array}{c}72 \\
(92,3 \%)\end{array}$ & $\begin{array}{c}78 \\
(100 \%)\end{array}$ \\
\hline
\end{tabular}

$* \alpha=0,05$

Berdasarkan tabel 2, terlihat bahwa terdapat $72,7 \%$ peserta kegiatan yang mengalami peningkatan pengetahuan (dari yang sebelumnya berada dalam ketegori kurang baik menjadi baik) dari total 22 orang yang pengetahuannya tergolong kurang baik. Hasil perhitungan Wilcoxon Signed Rank Test, menunjukan bahwa secara statistik terdapat perbedaan bermakna antara kelompok pre test dan post test, atau dapat dikatakan bahwa kegiatan penyuluhan yang dilakukan berhasil meningkatkan pengetahuan peserta mengenai ketahanan pangan.

Pengetahuan yang baik dapat menjadi salah satu kunci penting terjadinya perubahan perilaku. Berhubungan dengan hal ini, pengetahuan yang baik mengenai ketahanan pangan rumah tangga, diharapkan dapat menjadi kunci penting perubahan perilaku masyarakat terkait pangan dan gizi. Perubahan perilaku yang dimaksudkan disini adalah setiap individu semakin peduli dalam menjaga ketahanan pangan rumah tangganya dengan melakukan berbagai upaya seperti memanfaatkan pekarangan untuk menanam bahan makanan lokal dan menganekaragamkan konsumsi pangannya (BKP Kementan, 2018).

Ketahanan pangan bukan hanya mencakup ketersediaan bahan makanan di suatu daerah, tapi bagaimana bahan pangan itu mudah diakses oleh masyarakat serta pemanfaatnnya oleh setiap individu (BKP Kementan, 2018). Kondisi ini menunjukan pentingnya edukasi kepada masyarakat mengenai ketahanan pangan rumah tangga. Sehingga masyarakat akan lebih mengetahui bagaimana menyediakan bahan makanan sendiri melalui pemanfaatan pekarangannya, sampai pola konsumsi makan yang baik untuk pencegahan masalah gizi kronis karena semakin baik ketahanan pangan rumah tangga berarti asupan makan setiap anggotanya (khususnya balita) semakin baik (Adriani dan Wirjatmadi, 2012).

\section{KESIMPULAN DAN SARAN}

\section{Kesimpulan}

1. Penyuluhan tentang ketahanan pangan rumah tangga dapat meningkatkan pengetahuan Ibu Rumah Tangga tentang pentingnya ketahanan pangan rumah tangga. 
VIVABIO

Jurnal Pengabdian Multidisiplin

2. Pengetahuan yang meningkat tentang ketahanan pangan rumah tangga, diharapkan dapat membantu upaya pencegahan masalah gizi kronis (stunting).

\section{Saran}

Perlu diadakan kegiatan penyuluhan yang berkelanjutan pada kelompok masyarakat, terutama untuk daerah yang rawan pangan agar bisa mendorong terjadinya perubahan perilaku.

\section{UCAPAN TERIMA KASIH}

Terima kasih kepada Lembaga Penelitian dan Pengabdian Masyarakat Universitas Sam Ratulangi (LPPM Unsrat) yang telah mendanai kegiatan Program Kemitraan Masyarakat tahun pendanaan 2019.

Terima kasih kepada ketua dan semua anggota Wanita Kaum Ibu (WKI) Jemaat Immanuel Dame atas kerjasamanya sebagai mitra dalam kegiatan PKM ini dan membantu pelaksanaannya.

\section{DAFTAR PUSTAKA}

Adriani, M., Wirjatmadi, B., 2012. Peranan

Gizi Dalam Siklus Kehidupan, I. ed.

Kencana Prenada Media Group, Jakarta.
Balitbangkes, 2013. Riset Kesehatan Dasar Tahun 2013. Jakarta.

BKP Kementan, 2018. Peta Ketahanan dan Kerentanan Pangan Indonesia (A Food Security and Vulnerability Atlas of Indonesia). Jakarta.

Hapsari, N.I., Rudiarto, I., 2017. FaktorFaktor yang Mempengaruhi Kerawanan dan Ketahanan Pangan dan Implikasi Kebijakannya di Kabupaten Rembang. J. Wil. dan Lingkung. 5, 125. https://doi.org/10.14710/jwl.5.2.125140

Masrin, Paratmanitya, Y., Aprilia, V., 2014. Household food security correlated with stunting in children 6-23 months. J. Gizi dan Diet. Indones. (Indonesian J. Nutr. Diet. 2, 103-115.

Pee, S. de, 2013. Food Security. Encycl. Hum. Nutr. 2, 353-360.

Presiden RI, 2012. Undang-Undang Nomor 18 Tahun 2012 Tentang Pangan. Indonesia.

WFP, 2009. A Food Security and Vulnerability Atlas of Indonesia, World. Dewan Ketahanan Pangan, Departemen Pertanian RI \& WFP, Jakarta. 